\title{
Evaluation of Disaster Resilience Preparation in the Construction Education Curriculum
}

\section{Dr. Sanjeev Adhikari, Kennesaw State University}

Dr. Sanjeev Adhikari is faculty from Kennesaw State University. Previously he was faculty at Morehead State University from 2009 to 2016 and faculty at Purdue University - Indianapolis from 2016 to 2019. He has completed Ph.D. degree in civil engineering, focusing on construction management from Michigan Technological University in 2008. He has an extensive teaching background with a total of 18 years academic experience at five different universities. He has always been praised by students and department for his outstanding teaching and research excellence. To supplement his teaching and research, he has been involved in numerous professional societies, including ASCE, ACI, ASEE, ASC, ATMAE and TRB. His research output has been well disseminated as he has published thirty journal papers and thirty-nine conference papers. His research interests are 1) Creating Innovative Sustainable Materials, 2) Structural BIM Integration, 3) 4D/5D BIM, 4) Virtual Testing Lab, 5) Innovative Construction Demolition, and 6) Carbon Footprint Analysis on Roadways.

\section{Dr. Rachel D. Mosier, Oklahoma State University}

Dr. Rachel Mosier is an Assistant Professor at Oklahoma State University and is licensed as a professional engineer in Construction and Structural Engineering. Her masters and doctoral degrees are from the University of Oklahoma in Construction Administration and Engineering respectively.

\section{Dr. Sandeep Langar, The University of Texas at San Antonio}

Dr. Sandeep Langar is an Assistant Professor in the Department of Construction Science in College of Architecture, Construction, and Planning at The University of Texas at San Antonio. He received his Ph.D. in Environmental Design and Planning from College of Architecture and Urban Studies at Virginia Tech. He is also a licensed architect in India. Dr. Langar has authored multiple publications analyzing the implementation of Building Information Modeling (BIM) and its impact on the adoption of Innovations towards Sustainability (ITS) among Architecture Engineering and Construction (AEC) stakeholders. He is also interested in identifying factors that lead towards the adoption of ITS among various stakeholders such as owners, architects, contractors, engineers, and others. Dr. Langar aims at identifying means and methods by which built environment can develop a symbiotic relationship with the ecosystem and in the process become resilient to natural hazards. 


\title{
Evaluation of Disaster Resilience Preparation in the Construction Education Curriculum
}

\begin{abstract}
The paper examines student perceptions for the resilience of the built environment towards natural disasters and the information sources to determine how teaching and assessment may be adapted to promote resilience within the curriculum. Resilience is related to construction as it is considered vital in the built environment. The research addresses wide-ranging definitions of resilience, encompassing endurance and adaptability, and seeks to understand how these definitions impact the learning experiences of students. The survey questions are used to determine how the students perceive natural disasters such as Avalanches, Landslides, Earthquakes, Floods, Hurricanes, Winter Storms, Sinkholes, Tornadoes, Tsunami, Volcanic eruptions, Tropical Storms, and Droughts. An online survey instrument was created to circulate among construction industry students to a) evaluate their experience of natural disasters, b) examine the source of knowledge of resilience on natural disasters, c) measure knowledge of post-disaster evacuation, and d) evaluate disaster preparation from university education. The study found that the population of the student body existed that had not experienced a natural disaster and were unaware of its impacts either on a personal or familial basis. Further, the majority of the responding students felt that their major(s) and universities did not prepare them in terms of handling natural disasters and extreme weather events. Finally, a correlation was found between the location students live and a desire for knowledge about extreme weather events at the college level.
\end{abstract}

Keywords: Resilience, Resilience Education, Civil Engineering, Disaster Response

\section{Introduction and Background}

The impacts of natural disasters have been observed globally, including the changes to the worldwide climate and the ecosystems [1], [2], [3]. During 1996-2015, 11,000 extreme events occurred globally, resulting in fatalities exceeding half a million, and direct economic losses exceeding three Trillion USD. Also, from 2006 to 2015, China, US, India, Indonesia, and the Philippines, were the top five countries across the globe impacted by natural disasters [2], [3]. Within the US, in the last 38 years (1980-2018), the most frequent and most expensive BillionDollar disaster events occurred in the last decade [4]. Further, 2019 emerged as the fifth consecutive year for 2015-2019, where the losses due to the climatic events impacting the US resulted in losses exceeding ten billion dollars [4]. Thereby indicating that the US is not only one of the top countries impacted by natural disasters, but also the natural disasters impacting the country are becoming more severe and intense.

Natural disasters impact not only the Architecture, Engineering, and Construction (AEC) industry but also the social system and the future financial independence of society [5]. Natural disasters can impact the economic value of the property (short-term) and the impact on the wealth distribution of society. After the occurrence of a natural disaster, first responders, public works departments, and contractors support the restoration of the built environment that supports the social system of the impacted areas. These weather events frequently cause cost changes in the construction market as drywall, plywood, and roofing are replaced [6], [7], [8]. As weather patterns intensify, the construction industry is often responsible for a large portion of the clean-up. Public 
Works officials follow closely behind Police, Fire, and Ambulance services to disaster zones. Demolition contractors can be involved with owners, insurance companies, or public contracts. Architects, engineers, and home builders are expected to create more resilient structures and infrastructure. Indications exist that society is open towards the incorporation of technologies and strategies that can enhance the resilience of the built environment in response to natural disasters [9], [10]. Resilient structures are becoming a critical component of being prepared for future extreme events and alleviating the impacts of natural disasters [11]. Research also indicates that owners are perceptive towards the implementation of technologies and strategies that enhance the resilience against natural disasters [10]. Further, the need for such structures is exasperated when the majority of people believe that natural disasters can impact their community in the next year [11]. Thus, depicting the need for professionals within the AEC industry that are not only adept at design and construction of buildings that are resilient but also contributing during the post-disaster recovery.

Construction students may be aware of weather events and may be impacted by them in their personal lives. However, it is unknown if construction students recognize a relationship between weather events and the construction industry. Further, the level of resilience education offered to students enrolled in the construction curriculum across the US is unknown. There is evidence that resilience education is imperative but is lacking globally [12], [13]. There are limitations in the area of available research capabilities in societal resilience [14]. At the same time, while the introduction of education is essential, it is equally paramount to ascertain the student perceptions for the resilience of the built environment towards natural disasters and the sources of information. Construction students, especially those that reside in locations that are impacted by severe weather, need to not only have an understanding of the societal impacts but the impact on the industry. As weather events become more frequent and intense, the construction industry has to react to repair, rebuild, and understand the impact on cost and schedule of on-going projects.

\section{Methodology}

The study used a survey method to determine student experiences with natural disaster(s), examine source(s) of knowledge for resilience against natural disasters, measure knowledge about postdisaster evacuation, and evaluate disaster preparation obtained through the university education. The survey was conducted online as it allowed researchers to identify the student's current perceptions and knowledge at the point of time. Also, the online survey was selected as the majority of the population, including the students, have access to emails [15], and the method allowed documentation of responses at a faster rate in comparison to other survey methods. The population for the study was students enrolled in construction programs across the states of Texas, Oklahoma, and Georgia. The three states were purposely selected from a list of six states (Texas, Oklahoma, North Carolina, Illinois, Alabama, and Georgia) that were most impacted by the Billion-Dollar Weather and Climate Disasters during the period of 1980-2019 [4]. The six states for 39 years were impacted by 514 disasters [4]. Qualtrics was used as the platform of the data collection. The online survey had four sections, including the respondent's consent, demographics, knowledge, and perceptions. The survey consisted of multiple-choice, Likert scale, and slider scale questions. The survey was designed in such a manner that it could be completed within ten minutes. After the design of the survey, it was subjected to a pilot study, and all recommendations from the 
pilot test were incorporated into the study. The survey was active for four months, during which 164 students participated in the study.

\section{Results and Discussion}

At the time of the study, all 164 responses were downloaded, including responses from 35, 61, and 68 students from the states of Georgia, Oklahoma, and Texas, respectively. The subsequent section discusses the responding student's demographics, knowledge, and perceptions for the natural disasters experienced by the responding students.

\section{$\underline{\text { Demographics }}$}

To determine the type of weather to which the respondents may be exposed, students were asked to identify the state in which they permanently resided and the state in which the university was located. Except for three out of state students (NC, VA, MO), the majority were from the same states as the universities they attend, as depicted in Figure 1. The home state is identified as a permanent residence.

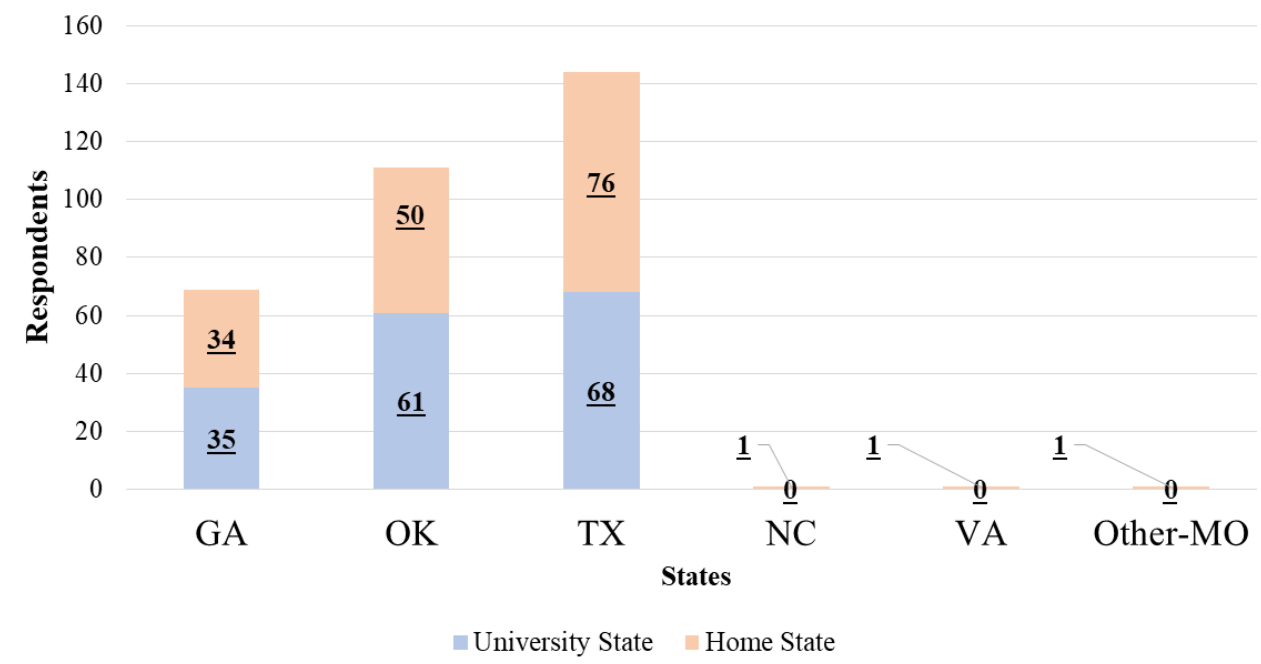

Figure 1: Respondents from each state

Further, to ascertain the level of studies and degree programs, respondents were asked to identify the year in which they were enrolled and their major field of study. Approximately $95.7 \%$ of the respondents were undergraduate students. Students who did not respond to this question were assigned a response of " $N / A$." Of the students that identified themselves as undergraduates The majority of the respondents $(47.8 \%$ or 75 out of the 157 students) identified themselves as seniors, as indicated in Figure 2. 


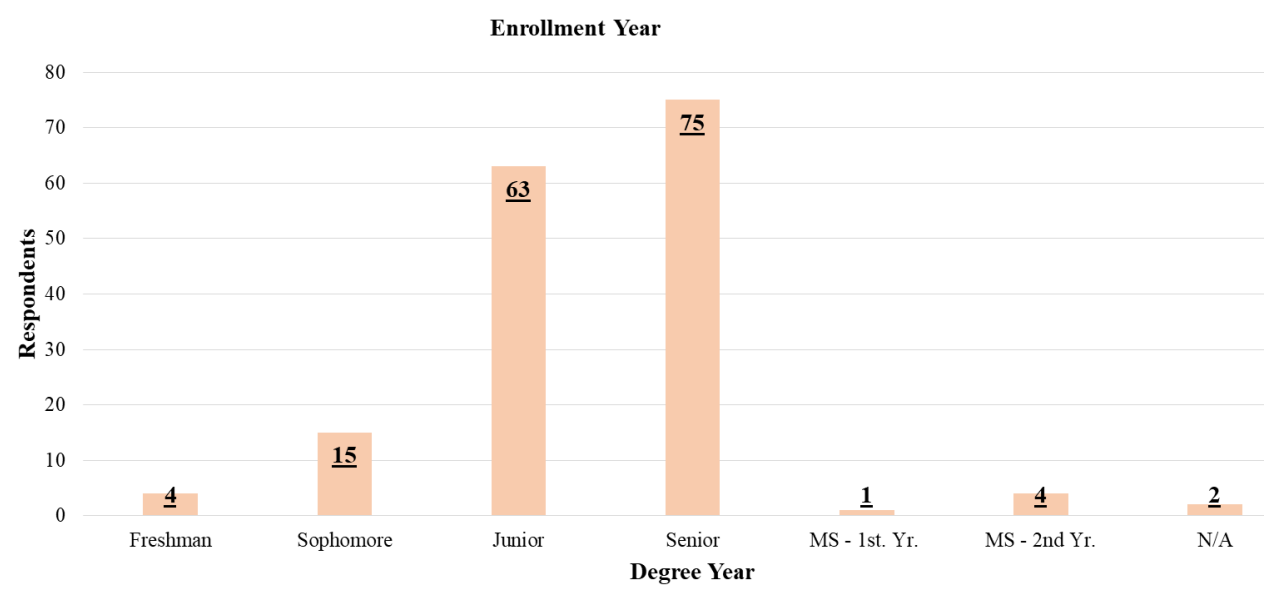

Figure 2: Respondent university degree level

The respondents were enrolled in a variety of degree programs or majors, which included Architecture, Architecture Engineering, Construction Engineering, Construction Engineering Technology, Construction Management, Construction Science, Building Construction, and others. The students selecting "Other" all self-identified their degree as Civil Engineering. The largest group of respondents was enrolled in Construction Management, with 56 responses (34.1\%). The majority of respondents $(76.8 \%)$ were associated with Construction majors. There were $38(23.2 \%)$ remaining respondents representing Architecture, Architecture Engineering, and Civil Engineering, as depicted in Figure 3.

The study further aimed to ascertain the exposure of the respondents to natural disasters by enquiring if they had personally experienced natural disasters, and if someone in their family had experienced the same in the last ten years. The responses for an individual experience with natural disasters are indicated as "Personal" in Figure 4. Further, the responses with someone in the family experiencing natural disasters in the last ten years are indicated as "Familial." Student respondents had experienced fewer disasters than their families, which might be expected. Nearly $41 \%$ of Students reported "Personal" experiences with natural disasters as and $60.9 \%$ reported "Familial" experiences with natural disasters. Therefore, indicating that the population of the student body existed that had not experienced a natural disaster and were unaware of its impacts either on a personal or familial basis.

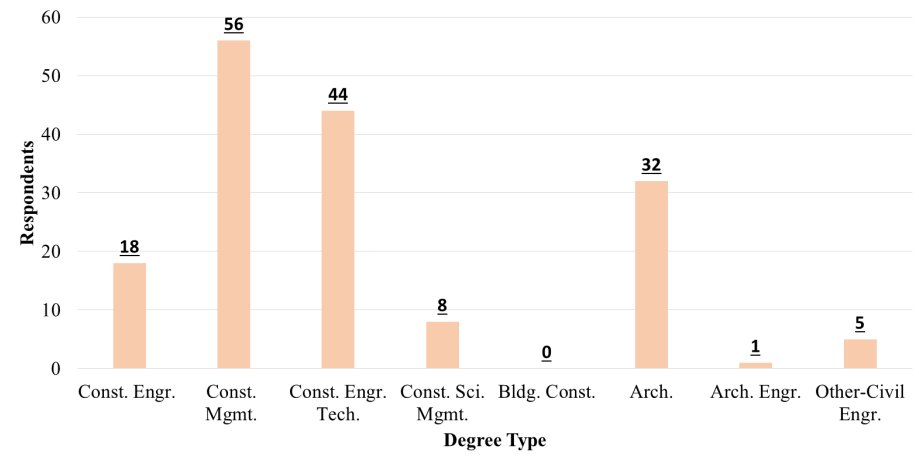

Figure 3: Respondent degree type

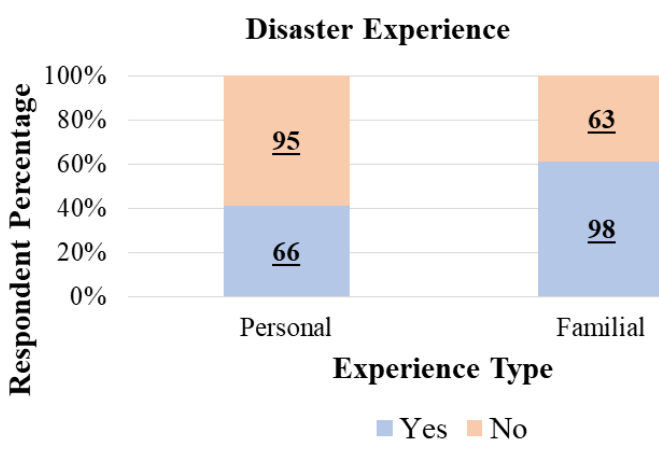

Figure 4: Experiences with weather events 
Natural disasters experienced by the students correspond closely with those experienced by their families. The students were further asked to identify the natural disasters experienced in the last ten years on a personal and familial basis. Incident occurrence for families was 210 versus 164 occurrences experienced by students (personal) or 1.28 times more frequent, as depicted in Figure 5 . The occurrence number can surpass the total number of respondents because the respondents could be impacted by more than one weather event type. The increase in occurrence also relates directly to the responses to whether students or their families had experience with weather events. High occurrences of hurricanes, floods, tropical storms, and tornadoes could be explained by the fact that the majority of the responding students were predominantly from Georgia, Oklahoma, and Texas.

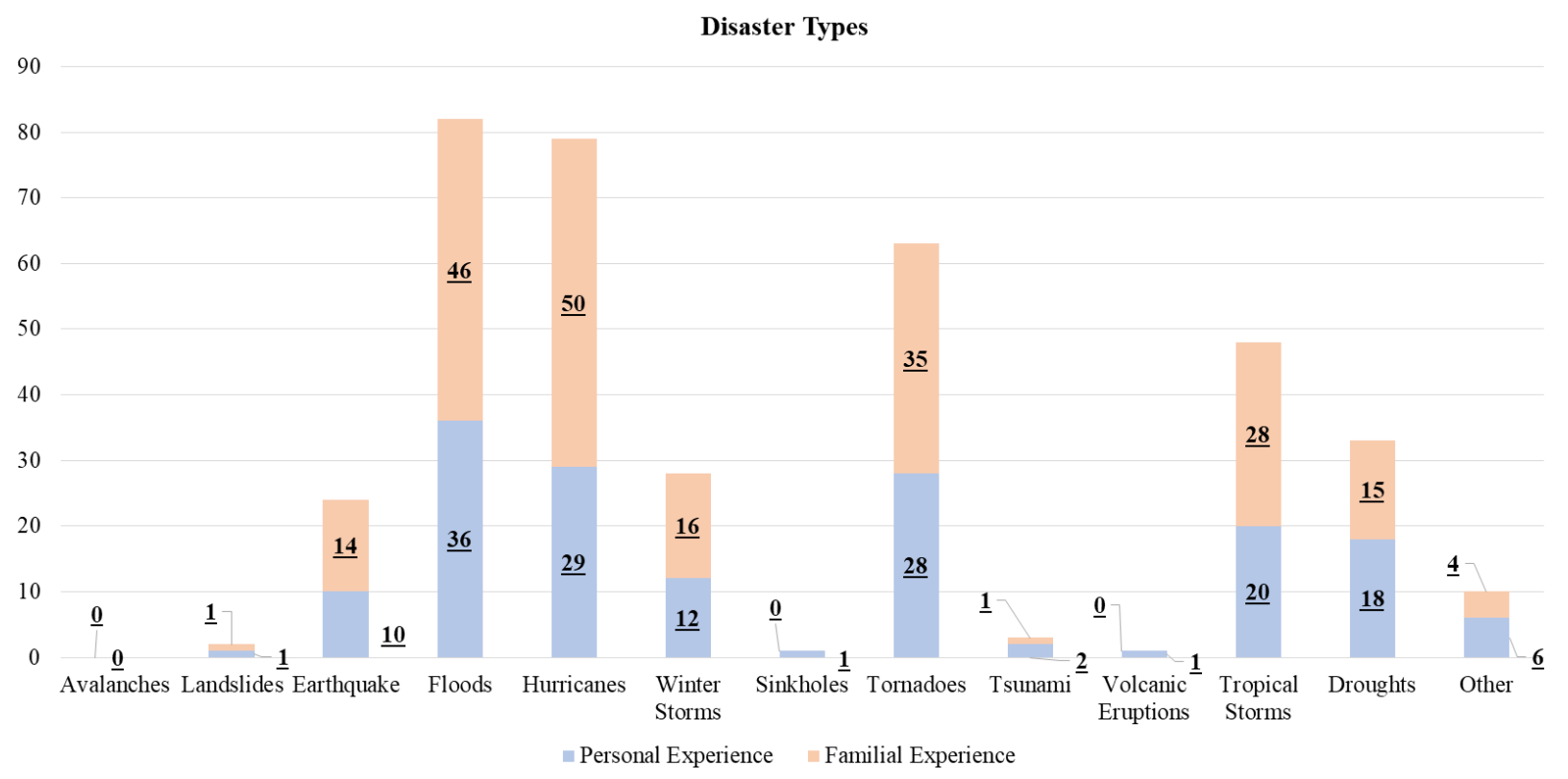

Figure 5: Number of Weather Events to which Students or Families have been exposed

\section{Knowledge}

The knowledge-based questions focused on whether students believed their education prepared them for severe weather events and disasters. Approximately $48.8 \%$ of the responding students identified that the education provided in their major(s) prepared them for natural disasters that might impact them in the near future, as depicted in Figure 6. Further, $46.6 \%$ of the responding students identified that the education provided in their university prepared them for natural disasters, as depicted in figure 6. Although some respondents indicated that their major provided some weather education, fewer believed the university was providing education about extreme weather events. Therefore, indicating that the majority of the students felt that their major(s) and universities did not prepare them in terms of handling natural disasters and extreme weather events. Such a finding is concerning, primarily when the students will actively be associated with the construction industry.

The students were also asked about their knowledge (provided by the department) for the level of confidence possessed as a member of the society in dealing with a natural disaster that might impact them the most. The majority of the respondents identified their confidence as "probably yes," as depicted in Figure 7. The students were also asked about their knowledge (provided by the 
department) for the level of confidence possessed as a construction professional in dealing with a natural disaster that might impact them the most. The majority of the respondents identified their confidence as "might or might not," as depicted in Figure 7. These were based on a 5-point Likert scale. The responses shown in Figure 7 indicate the level of knowledge as a typical member of society on the bottom versus those as a construction professional shown above. In both cases, more than $40 \%$ of the respondents indicated that they were prepared for severe weather as a general member of society and as a construction professional. At the same time, another point worth noting is that the majority of the responding students were unsure when it comes to the level of confidence possessed as a construction professional in dealing with a natural disaster that might impact them the most. Therefore, highlighting the need for not only imparting the education at the university/major/departmental level but also preparing the students for unanticipated scenarios that might be generated by future natural disasters or climatic events.

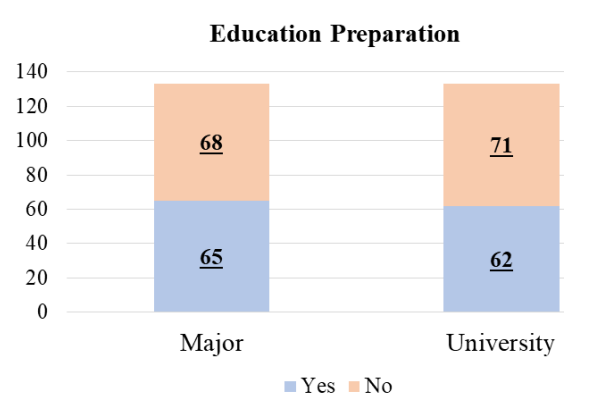

Figure 6: Respondents perception of education preparation

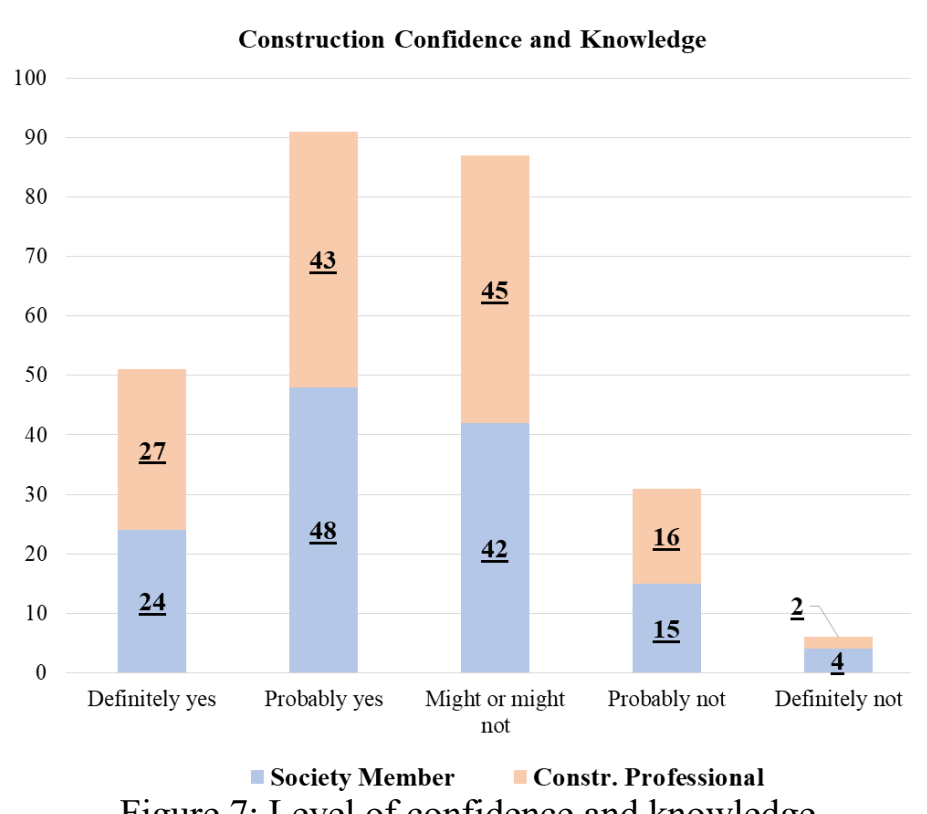

Figure 7: Level of confidence and knowledge

\section{$\underline{\text { Perception }}$}

The perception-based questions focused on student perception of resiliency in construction and its association with their college education. Approximately $62 \%$ of respondents indicated familiarity with the concept of resilient buildings, as depicted in Figure 8a. This is an area identified for universities to add focus. Further, $94 \%$ of students indicated that building resiliency concepts should be taught in college, as depicted in Figure 8b. Respondents also indicated a strong response of $86.0 \%$ for teaching post-disaster evacuation of natural disasters and implementation in college, as depicted in Figure 8c. 


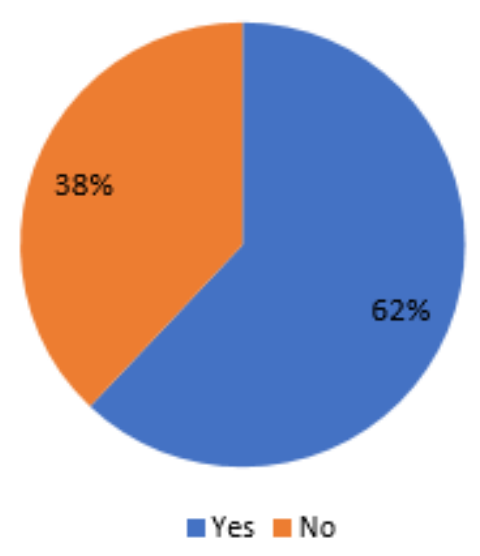

a) Resilience Concepts

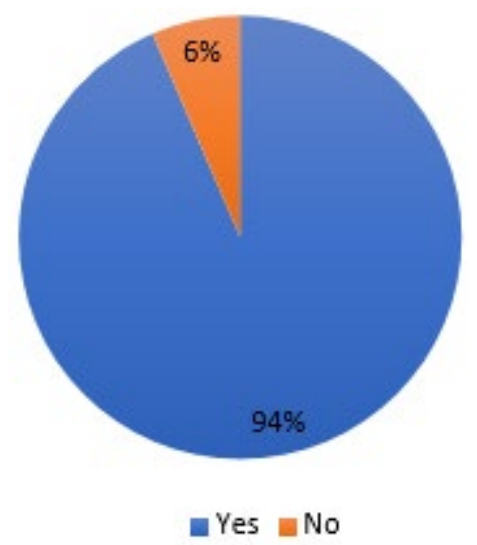

b) Resilience Knowledge

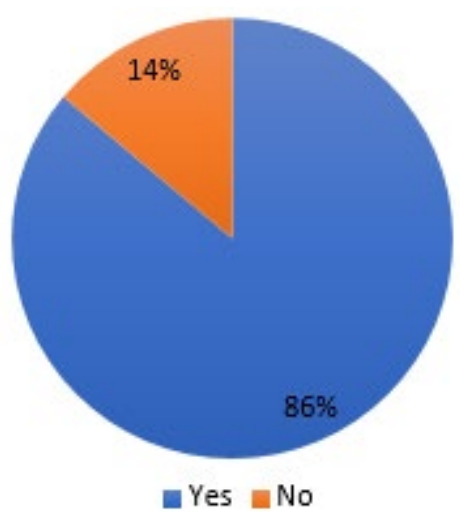

c) Evacuation Concepts

Figure 8: Student Perceptions of Resilience and Evacuation

\section{Additional Analyses:}

JMP software was used to conduct additional analyses. The p-value determined by JMP is the probability of a quantile in a distribution. Both the Likelihood Ratio and Pearson p-values were determined. A Likelihood Ratio (LR) and Pearson chi-squared test of the independence of the response variables were performed. Further, an additional calculation was performed to determine the association between the survey response variables or Cramer's V. Cramer's V indicates how closely the variables are associated based on values of zero and one. A full Cramer's V of 1 indicates complete association. Cramer's V is given as the square root of the Pearson chi-squared value divided by the number of responses again divided by the number of columns or rows minus 1. JMP defines the degrees of freedom as the number of responses minus 1 , so it is helpful in the Cramer's V calculation.

When considering correlations of significance, comparing responses from the question on the major field of study design for respondents and questions about family experiences with natural disasters, there was an LR chi-squared relationship equal to 25.08, a Pearson chi-squared relationship equal to 53.95, the degrees of freedom $(\mathrm{df})=14,0.0337$ and a Pearson $p$-value $<0.0001$. However, this is a spurious correlation. A Cramer's V value of 0.305 was found, indicating a low association. The family experience question is more statistically significant when compared to familial experience than the question about personal experiences with natural disasters. This correlation indicates that families have more experiences with weather events.

There is a strong correlation between the states where students attended university and knowledge of resilient buildings. There is an LR chi-squared relationship equal to 59.42, a Pearson chi-squared relationship equal to $197.25, \mathrm{df}=9$, and both the $\mathrm{LR}$ and Pearson $\mathrm{p}$-value $<0.0001$ with the majority of the respondents indicating agreement. A Cramer's V value of 0.657 was found, indicating an association between variables. The majority of respondents from Texas and Georgia indicated an understanding of resilient buildings. However, the group from Oklahoma was almost equally split on their resiliency knowledge. There is a similar relationship between the state of permanent 
residence and knowledge of resilient buildings, indicating that where students are from and their knowledge of building resiliency are related.

Comparing questions focused on where students attended university and student perception of natural disasters building resiliency and implementation, there is LR chi-squared relationship equal to 54.68, a Pearson chi-squared relationship equal to $192.995, \mathrm{df}=9$, and both the LR and Pearson $\mathrm{p}<0.0001$. A Cramer's V value of 0.651 was found, indicating an association between variables. Students from Texas indicated a strong desire for resiliency and implementation to be taught at the university level, with $92.9 \%$ agreeing with the statement. Georgia respondents also indicated a strong desire, with $88.6 \%$ in agreement. A similar relationship was found between the state of permanent residence and student perception of natural disasters building resiliency and implementation.

When the question focused on where students attended university is compared with the question asking if respondents think post-disaster evacuation and implementation should be taught in college, the responses produce an LR chi-squared relationship equal to 53.86, a Pearson chisquared relationship equal to $192.924, \mathrm{df}=9$, and both the LR and Pearson $\mathrm{p}<0.0001$. This relationship is maintained when looking at when comparing permanent residence state and postdisaster evacuation and implementation with a $\mathrm{p}<0.0001$. A Cramer's V value of 0.650 was found, indicating an association between variables. Respondents from Georgia and Texas indicated that this should also be included in college curriculums with over $80 \%$ positive responses. Students from Oklahoma were not as positive in their responses. However, Georgia and Texas are coastal with hurricanes. This difference in the severity of weather events may also contribute to the difference in their responses.

Responses regarding natural disasters experienced in the last ten years to the three states of residence (GA, OK, and TX) were compared. Georgia students mostly experienced Floods, Winter Storms, and Tropical Storms. In comparison, Oklahoma students mostly experienced Tornadoes, Floods, Earthquake, and Winter Storms. Texas students have mostly experienced Hurricanes, Floods, and Tropical Storms. Figure 9 categorizes student response percentages of natural disasters experienced from GA, OK, and TX. 


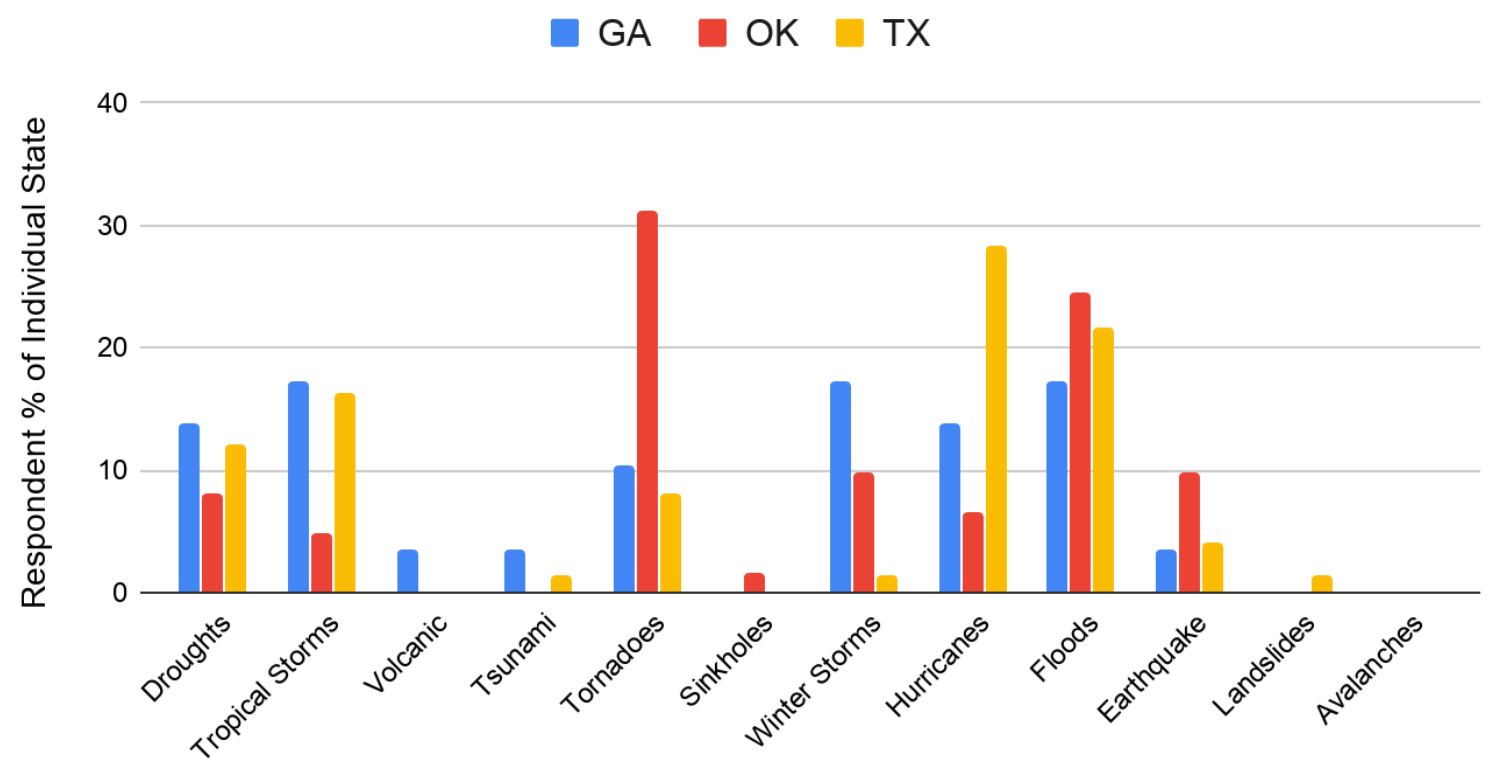

Experiences with natural disasters by student respondents

Figure 9: Respondent percentage of natural disasters experience from GA, OK, and TX.

\section{Conclusion}

The research questions are used to determine how the students perceive natural disasters such as Avalanches, Landslides, Earthquakes, Floods, Hurricanes, Winter Storms, Sinkholes, Tornadoes, Tsunami, Volcanic eruptions, Tropical Storms, and Droughts. When reviewing the locations of the respondents and their understanding of weather and building resiliency, it is evident that students in the three states studied have a stronger desire for knowledge about extreme weather events. Georgia students have mostly experienced Floods, Winter Storms, and Tropical Storms. Oklahoma students have mostly experienced Tornadoes, Floods, Earthquake, and Winter Storms. Texas students have mostly experienced Hurricanes, Floods, and Tropical Storms.

While examining the source of knowledge of resilience on natural disasters, some respondents indicated that their major provided some weather education, fewer believed the university was providing education about extreme weather events. Based on survey respondents, construction education is not preparing students well enough about resilience for natural disasters. While asking about student perception about resiliency in construction and its association with their college education, about $58.6 \%$ of respondents indicate familiarity with the concept of resilient buildings, and $94.7 \%$ of students indicated building resiliency concepts should be taught in college. Respondents had a strong response of $88.0 \%$, indicating post-disaster evacuation of natural disasters should be taught in college. The next steps and any future study should include a larger sample population with an investigation of the implementation of resilience in a construction curriculum. Educational outcomes would also be an area of interest for future research. 


\section{References}

[1] McLeman, R., and Smit, B. (2006). "Migration as an Adaptation to Climate Change." Climatic Change, 76, 31-53.

[2] Williams, J. W., Jackson, S. T., and Kutzbach, J. E. (2007). "Projected distributions of novel and disappearing climates by 2100 AD." Proceedings of the National Academy of Sciences of the United States of America, 104 (14); 5738-5742.

[3] Mora, C., Frazier, A. G., Longman, R. J., Dacks, R. S., Walton, M. W., Tong, E. J., Sanchez, J. J., Kaiser, L. R., Stender, Y. O., Anderson, J. M., Ambrosino, C. M., Fernandez-Silva, I., Giuseffi, L. M., and Giambelluca, T. W. (2013). "The projected timing of climate departure from recent variability." Nature, 502, 183-187.

[4] NCDC-National Centers for Environmental Information (NCEI). (2019). Billion-Dollar Weather and Climate Disasters: Overview [Government]. https://www.ncdc.noaa.gov/billions/

[5] Goodman, L. S., and Christopher M. (2018). Homeownership and the American dream. Journal of Economic Perspectives 32 (1): 31-58. doi=10.1257/jep.32.1.31

[6] Todd, S. (1992). "Building Supplies Are Tight Since Hurricane Plywood, Shingles Hard to Get, Cost More." The Morning Call. Sept. 2, 1992. <https:/www.mcall.com/news/mcxpm-1992-09-02-2869158-story.html>

[7] Arnold, K. (2017). "Hurricane Irma: Plywood, lumber run short amid Orlando scramble to board up homes." Orlando Sentinel. Sept. 9, 2017. $<$ https://www.orlandosentinel.com/weather/hurricane/os-hurricane-irma-plywood20170908-story.html>

[8] Webb, C. (2018). "Hurricane Pushes Up Lumber Prices, While Fundamentals Point to Longer-Term Rise." ProSales Magazine. Sept. 11, 2018. 15 Faherty, T. B., Honeycutt, E. D., \& Powers, D. (1998). Exploring text-based electronic mail surveys as a means of primary data collection. 230-264.

[9] Mozumder, P., Chowdhury, A. G., Vásquez, W. F., \& Flugman, E. (2015). Household Preferences for a Hurricane Mitigation Fund in Florida. Natural Hazards Review, 16(3), 04014031.

[10] Langar, S. (2020). "Perceptions for Residential Resilience." Residential Building Design \& Construction Conference (RBDCC), Pennsylvania State University, PA, March 4-6, 2020.

[11] Leichenko, R., McDermott, M., \& Bezborodko, E. (2015). Barriers, Limits, and Limitations to Resilience. Journal of Extreme Events, 02(01), 1550002. https://doi.org/10.1142/S2345737615500025

[12] Perdikoua, S., Horakb, J., Palliyaguruc, R., Halounovád, L., Leesa, A., Ranguelove, B., and Lombardif, M. (2014). "The current landscape of disaster resilience education in Europe." Procedia Economics and Finance. 18; 568 - 575.

[13] Sakuraia, A., Bisrib, M.B.F., Odac, T., Oktarid, R.S., Murayamae, Y., Nizammudin, and Affang, M. (2018). "Exploring minimum essentials for sustainable school disaster preparedness: A case of elementary schools in Banda Aceh City, Indonesia." International Journal of Disaster Risk Reduction. 29; 73-83.

[14] Thakore, R., Liyanage, C., Amartunga, D., Haigh, R., and Mustapha, A. (2017). "Strengthening Skills in Research Methods in Higher Education Institutions to Improve Societal Resilience to Disasters." Procedia Engineering. 212; 946-953. 
[15] Sheehan, K. B. (2001). Email Survey Response Rates: A Review. Journal of ComputerMediated Communication, 6(JCMC621). https://doi.org/10.1111/j.10836101.2001.tb00117.x 